\title{
Correction to: Validity of the Italian multiple sclerosis neuropsychological screening questionnaire
}

\author{
Simone Migliore ${ }^{1} \cdot$ Doriana Landi $^{2}$ - Francesca Proietti ${ }^{2,3} \cdot$ Giulia D'Aurizio $^{3} \cdot$ Ferdinando Squitieri $^{1}$. \\ Giorgia Mataluni ${ }^{2} \cdot$ Carolina Gabri Nicoletti $^{2} \cdot{\text { Giuseppe } \text { Curcio }^{3} \text { - Girolama Alessandra Marfia }}^{2,4}$
}

Published online: 11 March 2021

(C) Fondazione Società Italiana di Neurologia 2021

\section{Correction to: Neurological Sciences (2021) https://doi.org/10.1007/s10072-021-05141-1}

The original article contains an error in author name. In the published article, author name Girolama Alessandra Marfia was incorrectly captured as GirolamaAlessandraAlessandra Alessandra Marfia. Author name is corrected above.

The original article has been corrected.

Publisher's note Springer Nature remains neutral with regard to jurisdictional claims in published maps and institutional affiliations.

The online version of the original article can be found at https://doi.org/ 10.1007/s10072-021-05141-1

Simone Migliore

sim.migliore@gmail.com

1 Huntington and Rare Diseases Unit, Fondazione IRCCS Casa Sollievo della Sofferenza, San Giovanni Rotondo, Italy

2 Multiple Sclerosis Clinical and Research Unit, Department of Systems Medicine, University of Rome Tor Vergata, Rome, Italy

3 Department of Biotechnological and Applied Clinical Sciences, University of L'Aquila, L'Aquila, Italy

4 Unit of Neurology, IRCCS Istituto Neurologico Mediterraneo NEUROMED, Pozzilli, IS, Italy 